\title{
Burden, etiology and predictors of visual impairment among children attending Mulago National Referral Hospital eye clinic, Uganda.
}

\author{
Patience Kinengyere*, Samuel Kizito*, John Baptist Kiggundu, Anne Ampaire, Geoffrey Wabulembo
}

\section{Makerere University College of Health Sciences}

*the authors contributed equally

Kinengyere Patience: pkinengyere@yahoo.com

Kizito Samuel: somekizito@yahoo.com

Kiggundu John Baptist: jbkiggundu5@gmail.com

Ampaire Anne: annemukisa@gmail.com

Wabulembo Geoffrey: wabulemboh@yahoo.com

\begin{abstract}
Background: Childhood visual impairment (CVI) has not been given due attention. Knowledge of CVI is important in planning preventive measures. The aim of this study was determine the prevalence, etiology and the factors associated with childhood visual impairment among the children attending the eye clinic in Mulago National Referral Hospital.

Methods: This was a cross sectional hospital based study among 318 children attending the Mulago Hospital eye clinic between January 2015 to March 2015. Ocular and general history was taken and patient examination done. The data generated was entered by Epidata and analyzed by STATA 12.

Results: The prevalence of CVI was $42.14 \%, 134$ patients with 49 patients (15.41\%) having moderate visual impairment, 45 patients $(14.15 \%)$ having severe visual impairment and 40 patients $(12.58 \%)$ presenting with blindness. Significant predictors included; increasing age, delayed developmental milestones and having abnormal corneal, refractive and fundus findings.

Conclusion: There is a high burden of visual impairment among children in Uganda. It is vital to screen all the children presenting to hospital for visual impairment. Majority of the causes of the visual impairment are preventable.
\end{abstract}

Keywords: Visual impairment, Mulago National Referral Hospital, Eye clinic, Uganda.

DOI: https://dx.doi.org/10.4314/ahs.v17i3.31

Cite as: Kinengyere P, Kizito S, Kiggundu JB, Ampaire A, Wabulembo G. Burden, etiology and predictors of visual impairment among children attending Mulago National Referral Hospital Eye Clinic, Uganda. Afri Health Sci. 2017;17(3): 877-885. https://dx.doi.org/10.4314/ahs. $v 17 i 3.31$

\section{Introduction}

Visual impairment includes low vision as well as blindness. Low vision is defined as visual acuity of less than $6 / 18$, but equal or better than $3 / 60$, or a corresponding

\section{Corresponding author:}

Samuel Kizito, Clinical Epidemiology Unit, School of Medicine, College of Health Sciences, Makerere University, Kampala Uganda.

Mobile :+256 702453 417/ 773756372

Email: somekizito@yahoo.com

/mskizito@.chs.mak.ac.ug visual field loss to less than 20 degrees in the better eye with best possible correction. Blindness is defined as visual acuity of less than $3 / 60$, or corresponding visual field loss to less than 10 degrees in the better eye with the best possible correction. ${ }^{1}$

Globally, 1.4 million children are estimated to be blind, one fifth of whom are from Africa. ${ }^{2}$ A child goes blind every minute and the most at-risk are those children below 5 years of age. About $60 \%$ of the children die within one year of becoming blind. ${ }^{3}$ Childhood visual impairment has a lifelong impact to the patient, which makes it a significant problem. ${ }^{4}$ In the Low and Middle Income Countries (LMIC), up to $72 \%$ of the blindness is preventable while up to $31 \%$ is treatable. ${ }^{2}$

World Health Organization WHO through "The Right

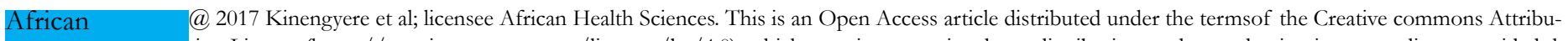

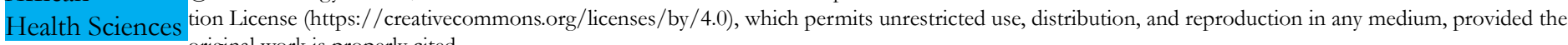
original work is properly cited.
} 
to Sight" global initiative prioritizes childhood blindness as one of the five conditions for control by $2020 . .^{5} \mathrm{Ap}-$ proximately $90 \%$ of visually impaired children in LMIC do not attain formal education. Childhood blindness has devastating implications not only for the affected child but the family as well. The devastation is lifelong and profoundly impacts negatively on educational, employment, personal, and social prospects. ${ }^{6}$. The quality of life of the visually impaired children is tremendously compromised given the number of Blind Person Years (BPYs) ahead of them. ${ }^{7}$

Despite the devastation childhood visual impairment CVI can cause and the noticeable increase in the number of children presenting with CVI in Mulago National Referral Hospital over recent years, the condition has not been given due attention. There is paucity of literature regarding the burden of visual impairment in Uganda. Our study aimed at assessing the burden, etiology and predictors of visual impairment among children presenting to Mulago hospital eye clinic. The findings from our study have given some insight into the magnitude of the burden of childhood visual impairment in Uganda and highlight key areas in reducing preventable causes of blindness in children.

\section{Methods}

\section{Study design and study setting}

This was a cross sectional study conducted in the eye clinic of Mulago National Referral Hospital.

Mulago National Referral Hospital is located in Kampala, the capital city. It has a capacity of about 1500 beds. The hospital also serves as a teaching hospital for Makerere University College of Health Sciences. The hospital has two eye clinics. The ophthalmology department has a clinic run by ophthalmic clinical officers. It is the first point of contact with the patients unless they are referrals from the other health units. The second clinic is a consultation clinic and is run by the ophthalmologists. The department has ten dedicated ophthalmologists, two of whom are pediatric ophthalmologists.

\section{Study population}

We conducted this study among patients below the age of 18 years who presented to the eye clinic at Mulago National Referral Hospital during the months of January to March 2015. We excluded any patient who was too sick to withstand the rigorous examinations during the study period.

\section{Sampling and sample size calculation}

We employed systematic sampling, taking every second pediatric patient seen at the clinic each day. The clinic receives an average of 75 pediatric patients per week. The first patient was randomly selected each day, and then every second pediatric patient eligible for the study was enrolled upon consenting. The research assistant helped to identify the proposed patients.

Using the the Kish Leslie's formula ${ }^{8}$, we estimated the sample size of 318 patients for the study using a prevalence of $29.3 \%$ ?

\section{Study procedures}

We conducted a baseline visual acuity to ascertain whether the child had visual impairment. The visual acuity test used was according to the age of the child.

Children 5 years and above who could read were assessed using the Snellen's chart. Pre-verbal children were tested using 'preferential looking' techniques. Children 18 months to 60 months were assessed using the Cardiff test. In the children 6-24 months, Lea Gratings were used to test visual acuity. ${ }^{10}$

All the study participants had a detailed history taken, general physical examination and ocular examination done. Standard ophthalmic equipment was used to do the examinations. These included tape measure to measure the head circumference, ophthalmoscope, retinoscope, slit lamp, examining torch, lid speculum and prism bars. Data was collected using a questionnaire. Examination of the lids, conjunctiva, cornea, anterior chamber, pupil and iris was done using a torch and slit lamp. Dilating of the pupils was done with cyclopentolate or tropicamide eye drops. Dilated indirect ophthalmoscopy was done in all study participants. Clycloplegic retinoscopy was done on all the study participants.

Any ocular anomaly detected during the patient assessment was documented and managed as appropriate. Any non-ocular anomaly detected during the patient assessment was documented and the needed specialty consulted on the course of management.

\section{Study variables}

Dependable variable: Childhood visual impairment. Visual impairment included low vision as well as blindness. We defined low vision as visual acuity of less than 
$6 / 18$, but equal or better than $3 / 60$, or a corresponding visual field loss to less than 20 degrees in the better eye with best possible correction. We defined blindness as visual acuity of less than $3 / 60$, or corresponding visual field loss to less than 10 degrees in the better eye with the best possible correction. ${ }^{1}$ We defined visual impairment to include low vision and blindness.

Independent variables: Socio-demographic factors: age, sex, address, socio-economic factors: occupation of parents, level of education of the parents, education of the child and clinical factors like history of systemic illnesses and ocular illnesses.

\section{Data management and analysis.}

Data collected was double entered in to the computer software using EpiData version 3.1. Data was cleaned and exported for analysis. We analyzed the data using the STATA version 12 . We summarized continuous data using measures of central tendency. Categorical variables were summarized into frequencies and percentages. Comparisons between the continuous variables were done using student t-tests or the Mann-Whitney $U$ test depending on the distribution of the data. While for the categorical data, we employed the Chi-squared tests.

To assess for the associated factors, we applied logistic regression mathematical modelling techniques. All the factors with a $\mathrm{p}$ value $\leq 0.20$ at bivariate analysis were included in the multivariate logistic regression as well.

Ethical considerations. We obtained approval to conduct the study from the Makerere University School of Medicine Research and Ethics Committee and the Uganda National Council for Science and Technology. We obtained Informed signed consent from the care takers of the children and additional assent from the children who were 8 years and above.

\section{Results}

Of the 318 patients enrolled in our study, 170 (53.46\%) were females. Majority of the participants, 129 (40.57\%) were below 5 years of age. Of all the parents to the participants, $93.40 \%$ of the parents/ guardians had formal education and $90.57 \%$ had a source of employment. De-

Table 1: Socio-demographic characteristics of 318 children below 18 years attending Mulago Hospital eye clinic, 2015

\begin{tabular}{|c|c|c|c|c|}
\hline Variable & Total n (\%) & Normal vision & $\begin{array}{l}\text { Visual } \\
\text { impairment }\end{array}$ & Pvalue \\
\hline \multicolumn{5}{|l|}{ Agc (years) } \\
\hline 13elow 5 years & $129(40.3)$ & $87(27.4)$ & $42(13.2)$ & 0.01 \\
\hline 5 to 12 years & $120(37.7)$ & $66(20.8)$ & $54(16.9)$ & \\
\hline Above 12 years & $69(21.7)$ & $31(9.8)$ & $38(11.9)$ & \\
\hline Paticnt is female & $170(53.5)$ & $102(32.1)$ & $68(21.4)$ & 0.41 \\
\hline \multicolumn{5}{|l|}{ Fthnicity } \\
\hline Bantu & $270(84.9)$ & $156(40.1)$ & $114(35.9)$ & 0.74 \\
\hline Hamites & $13(4.1)$ & $6(1.9)$ & $7(2.2)$ & \\
\hline Nilo-hamites & $12(3.8)$ & $7(2.2)$ & $5(1.6)$ & \\
\hline Nilotic & $23(7.2)$ & $15(4.7)$ & $8(2.5)$ & \\
\hline Child stays with parent/guardian & $304(95.6)$ & $175(55.3)$ & $129(40.6)$ & 0.96 \\
\hline Parent has formal education & $297(93.6)$ & $178(55.9)$ & $119(37.4)$ & 0.01 \\
\hline \multicolumn{5}{|l|}{ Parent's guardian's occupation } \\
\hline Uncmployed & $30(9.4)$ & $13(4.1)$ & $17(5.4)$ & 0.18 \\
\hline Employed & $288(90.6)$ & $171(53.8)$ & $117(36.8)$ & \\
\hline \multicolumn{5}{|l|}{ Child's cducation } \\
\hline Preschool age & $118(37.1)$ & $78(24.5)$ & $40(12.6)$ & 0.00 \\
\hline In school & $187(58.8)$ & $105(33.0)$ & $82(25.8)$ & \\
\hline Not in school & $13(4.1)$ & $1(0.3)$ & $12(3.8)$ & \\
\hline Used traditional eye medicine & $26(8.8)$ & $12(3.8)$ & $14(4.4)$ & 0.21 \\
\hline
\end{tabular}


tails are shown in table below.

Antenatal, perinatal and post-natal history.

Majority of the mothers to the participants, 296 (93.1\%) attended antenatal care at least once during the pregnancy and $76(23.9 \%)$ had history of febrile illness during pregnancy.

Of all the deliveries, $295(92.8 \%)$ were conducted by a trained personnel. A large proportion, $306(96.2 \%)$ of the participants had normal weight for age on presentation and $277(87.1 \%)$ of the participants had normal head po-

Table 2: Antenatal, natal and postnatal history of 318 children below 18 years attending Mulago Hospital eye clinic, 2015.

\begin{tabular}{|c|c|c|c|c|}
\hline Variable & Total n (\%) & $\begin{array}{l}\text { Normal } \\
\text { vision }\end{array}$ & $\begin{array}{l}\text { Visual } \\
\text { impairment }\end{array}$ & Pvalue \\
\hline Attended antenatal care & $296(93.1)$ & $172(54.1)$ & $124(39.0)$ & 0.80 \\
\hline Had febrile illness during pregnancy & $76(23.9)$ & $46(14.5)$ & $30(9.4)$ & 0.64 \\
\hline Mother has systemic illness & $7(2.2)$ & $5(1.6)$ & $2(0.6)$ & 0.47 \\
\hline \multicolumn{5}{|l|}{ Assistant at delivery } \\
\hline Trained & $295(92.8)$ & $170(53.5)$ & $125(39.3)$ & \multirow[t]{3}{*}{0.91} \\
\hline Not trained & $17(5.4)$ & $12(3.8)$ & $5(1.6)$ & \\
\hline Unknown & $6(1.9)$ & $2(0.6)$ & $4(1.3)$ & \\
\hline Baby was full term at delivery & $304(95.6)$ & $179(56.3)$ & $125(39.3)$ & 0.39 \\
\hline \multicolumn{5}{|l|}{ Birth weight } \\
\hline Normal & $305(95.6)$ & $181(56.3)$ & $124(39.0)$ & \multirow[t]{3}{*}{0.03} \\
\hline Underweight & $6(1.9)$ & $2(0.6)$ & $4(1.3)$ & \\
\hline Unknown & $7(2.2)$ & $1(0.3)$ & $5(1.6)$ & \\
\hline \multicolumn{5}{|l|}{ Oxygen therapy after delivery } \\
\hline No oxygen given & $288(90.6)$ & $172(54.3)$ & $116(36.5)$ & \multirow[t]{2}{*}{0.18} \\
\hline Oxygen was given & $24(7.6)$ & $11(3.5)$ & $13(4.1)$ & \\
\hline Has history of convulsions & $11(3.5)$ & $2(0.6)$ & $9(2.8)$ & 0.01 \\
\hline Delayed developmental milestones & $27(8.5)$ & $7(2.2)$ & $20(6.3)$ & 0.00 \\
\hline \multicolumn{5}{|l|}{ Anthropometry } \\
\hline Normal weight for age & $306(96.2)$ & $182(57.2)$ & $124(39.0)$ & 0.03 \\
\hline \multicolumn{5}{|l|}{ Hcad size } \\
\hline Normal & $308(96.9)$ & $181(56.9)$ & $127(39.9)$ & \multirow[t]{2}{*}{0.01} \\
\hline Big for age & $10(3.1)$ & $3(0.9)$ & $7(2.2)$ & \\
\hline Abnormal IIcad position & $41(12.9)$ & $13(4.1)$ & $28(8.8)$ & 0.00 \\
\hline
\end{tabular}

sition. Details are highlighted in table below.

Diagnosis presented by the study participants
From table 3, the commonest diagnosis made for the participants was ocular trauma, 61 19.2\%. Anatomically, the commonest ocular abnormality was pupillary reaction 
Table 3: Table showing classification of the diagnoses by etiology among 318 children below 18 years attending Mulago Hospital eye clinic, 2015.

\begin{tabular}{|c|c|c|c|c|}
\hline Variable & $\begin{array}{l}\text { Total n } \\
(\%)\end{array}$ & $\begin{array}{l}\text { Normal } \\
\text { vision }\end{array}$ & $\begin{array}{l}\text { Visual } \\
\text { impairment }\end{array}$ & p value \\
\hline \multicolumn{5}{|l|}{ Etiological classification of } \\
\hline Refractive errors & $22(6.9)$ & $14(4.4)$ & $8(2.5)$ & 0.00 \\
\hline Infections & $19(5.9)$ & $8(2.5)$ & $11(3.5)$ & 0.00 \\
\hline Trauma & $61(19.2)$ & $15(4.7)$ & $46(14.5)$ & 0.00 \\
\hline Inflammation & $46(14.2)$ & $45(14.2)$ & $1(0.8)$ & 0.00 \\
\hline Ncoplasm & $10(3.1)$ & $6(1.9)$ & $4(1.5)$ & 0.00 \\
\hline Benign lesions & $29(9.1)$ & $29(9.1)$ & $0(0.0)$ & 0.00 \\
\hline Cataract & $17(5.3)$ & $5(1.6)$ & $12(3.8)$ & 0.00 \\
\hline Squint & $41(12.9)$ & $30(9.4)$ & $11(3.5)$ & 0.00 \\
\hline Congenital ocular anomalies & $6(1.9)$ & $0(0.0)$ & $6(1.9)$ & 0.00 \\
\hline Others* $*$ & $67(21.1)$ & $31(16.9)$ & $36(26.9)$ & 0.00 \\
\hline \multicolumn{5}{|l|}{ Anatomical classification of } \\
\hline Abnormal External eye & $50(15.7)$ & $42(13.2)$ & $8(2.5)$ & 0.00 \\
\hline Abnormal corncal cxam & $57(17.9)$ & $6(1.9)$ & $51(16.0)$ & 0.00 \\
\hline Abnormal pupillary reaction & $76(23.9)$ & $1(0.3)$ & $75(23.6)$ & 0.00 \\
\hline Abnormal fundus findings & $30(9.4)$ & $3(0.9)$ & $27(8.5)$ & 0.00 \\
\hline
\end{tabular}

"other etiologies include: tumor, ptosis, chalazion, dermoid cyst, comeal ulcer, optic neuropathy, lid hemangioma, foreign bodty, molluscum contagiosum, nasolacrimal duct obstruction, keratoconus, nystagmus, cortical blindness, entropion, sickle cell disease, conjunctival growth, buphalmos, microphthalmos, microcomea. anophthalmos, diabetic retinaopathy, retinitis pigmentosa, uveitis, symblepharon

disorders found among $7623.9 \%$ of all the children.

Visual impairment

In total, we found 134 (42.1\%) of the participants having visual impairment, $49(15.4 \%)$ had moderate visual impairment, $45(14.2 \%)$ had severe visual impairment and
$40(12.6 \%)$ had blindness. Only $184(57.9 \%)$ participants had normal vision on presentation. We found high prevalence of visual impairment among children with delayed developmental milestones, among those with history of convulsions, and those with low birth weight. Details are 
Table 4: Prevalence of visual impairment among 318 children below 18 years attending Mulago Hospital eye clinic, 2015.

\begin{tabular}{|c|c|c|}
\hline Variable & Number & Prevalence 95\% CI \\
\hline Overall visual impairment & 134 & $42.836 .8-47.7$ \\
\hline \multicolumn{3}{|l|}{ Age } \\
\hline Below 5 years & 129 & $32.624 .9-41.2$ \\
\hline 5 to 12 years & 120 & $45.036 .2-54.1$ \\
\hline Above 12 years & 69 & $55.143 .0-66.6$ \\
\hline \multicolumn{3}{|l|}{ Duration of the presenting complaint } \\
\hline Less than a week & 85 & $50.024 .7-97.5$ \\
\hline Lasted a week or more & 233 & $50.024 .7-97.5$ \\
\hline \multicolumn{3}{|l|}{ Use of local medications for eyes } \\
\hline Used local eye medicine & 26 & $53.833 .8-72.7$ \\
\hline Did not use local eye medicine & 292 & $41.135 .6-46.7$ \\
\hline \multicolumn{3}{|l|}{ Antenatal attendance } \\
\hline Mother attended antenatal care & 296 & $37.58 .7-79.2$ \\
\hline Did not attend antenatal care & 22 & $41.936 .4-47.6$ \\
\hline \multicolumn{3}{|l|}{ Fever during pregnancy } \\
\hline Had a fever during pregnancy & 76 & $42.536 .2-49.1$ \\
\hline No fever during pregnancy & 242 & $39.528 .9-51.1$ \\
\hline \multicolumn{3}{|l|}{ Birthplace } \\
\hline Had a birth attendant & 295 & $42.136 .6-47.7$ \\
\hline Delivered in absence of a birth attendant & 17 & $33.30 .7-99.7$ \\
\hline \multicolumn{3}{|l|}{ Attaining developmental milestones } \\
\hline Attained milestones on time & 291 & $39.233 .7-44.9$ \\
\hline Delayed milestones & 27 & $74.153 .2-87.8$ \\
\hline \multicolumn{3}{|l|}{ History of convulsion } \\
\hline Patient has no history of convulsions & 307 & $39.934 .4-45.5$ \\
\hline Had history of convulsions & 11 & $81.842 .0-96.5$ \\
\hline \multicolumn{3}{|l|}{ Birth weight } \\
\hline Underweight & 6 & $85.725 .7-99.0$ \\
\hline Normal weight & 306 & $40.735 .5-46.3$ \\
\hline \multicolumn{3}{|l|}{ Gestation age } \\
\hline Term delivery & 304 & $40.835 .3-46.4$ \\
\hline Born before term & 14 & $57.115 .0-90.9$ \\
\hline
\end{tabular}

in table 4.

Predictors of visual impairment

As shown in table 5, we found the following factors to be significantly associated with visual impairment. Age, delayed attainment of the developmental milestones, having abnormal pupillary reaction, corneal exam as well as having abnormal fundus examination findings. 
Table 5: Factors associated with visual impairment among 318 children below 18 years attending Mulago Hospital eye clinic, 2015.

\begin{tabular}{|c|c|c|c|c|}
\hline \multirow[b]{2}{*}{$\begin{array}{l}\text { Characteristic } \\
\text { Agc }\end{array}$} & \multicolumn{2}{|l|}{ Bivariate Analysis } & \multicolumn{2}{|c|}{ Multivariate Analysis } \\
\hline & COR $(95 \%$ CI $)$ & Pvalue & aOR $(95 \%$ CI $)$ & P value \\
\hline Below 5 years & 1 & & 1 & \\
\hline 5 to 12 years & $1.7(1.0-2.8)$ & 0.05 & $5.5(1.4-22.4)$ & 0.02 \\
\hline Above 12 years & $2.5(1.4-4.6)$ & 0.00 & $14.6(3.2-6.2)$ & 0.00 \\
\hline Paticnt is a malc & $1.2(0.8-1.9)$ & 0.41 & $1.5(0.6-3.5)$ & 0.37 \\
\hline \multicolumn{5}{|l|}{ Antcnatal history } \\
\hline PC more than 7 dirys & $0.6(0.3 \quad 1.1)$ & 0.09 & & \\
\hline Did not use traditional cye modicine & $0.6(0.3-1.3)$ & 0.21 & & \\
\hline Did not attend antcnatal care & $0.8(0.2-3.6)$ & 0.80 & & \\
\hline No lever during pregnancy & $1.1(0.7-1.9)$ & 0.64 & & \\
\hline Mother had no systemic illness & $1.8(0.4-9.5)$ & 0.48 & & \\
\hline Mother was not taking any medications & $1.8\left(\begin{array}{ll}0.4 & 9.5\end{array}\right)$ & 0.48 & & \\
\hline \multicolumn{5}{|l|}{ Perinatal history } \\
\hline No tramed personncl at delivery & $1.2(0.4-3.6)$ & 0.77 & & \\
\hline Baby born preterm & $1.9(0.4-8.8)$ & 0.39 & & \\
\hline \multicolumn{5}{|l|}{ Birth weight } \\
\hline Normal & 1 & & & \\
\hline Underweight & $2.9(0.5-16.2)$ & 0.22 & & \\
\hline Given Oxygen therapy after birth & $18(0.84 .1)$ & 0.19 & $1.2(0.26 .4)$ & 0.81 \\
\hline Paticnt has history of convulsion & $6.8\left(\begin{array}{ll}1.4 & 31.9\end{array}\right)$ & 0.02 & & \\
\hline \multicolumn{5}{|l|}{ Developmental milestones } \\
\hline Delixyol developmental milestones & $4.4(1.8-10.8)$ & 0.00 & $19.1(1.0-404.9)$ & 0.05 \\
\hline Abnormal Wcight for agc & $7.3(1.6-34.1)$ & 0.01 & $0.8(0.0-31.4)$ & 0.88 \\
\hline Abromal Ilcight for agc & $6.6(1.4-30.8)$ & 0.02 & & \\
\hline Head big for age & $0.5(0.14 .6)$ & 0.52 & & \\
\hline \multicolumn{5}{|l|}{ Head position } \\
\hline Tiltod & 1 & & & \\
\hline Normal & $0.3(0.1-0.6)$ & 0.00 & & \\
\hline Chin left & $2.3(0.4-13.0)$ & 0.36 & & \\
\hline Ocular cxamination findings normal & 1 & & & \\
\hline Has abnormal cye cxam & $0.2(0.1-0.5)$ & 0.00 & & \\
\hline Abnormal corncal exam & $16.4(6.6-40.0)$ & 0.00 & $7.0(1.7-29.5)$ & 0.01 \\
\hline Abnormal refraction & $9.9(5.0-19.7)$ & 0.00 & $9.5(3.9-23.1)$ & 0.00 \\
\hline Has abnormal pupillary reaction & $130.3(17.6 \quad 967.2)$ & 0.00 & & \\
\hline Abroormal fundus exam & $15.2(4.5-51.4)$ & 0.01 & $9.3(1.9-45.1)$ & 0.01 \\
\hline
\end{tabular}

\section{Discussion}

\section{Prevalence of childhood visual impairment.}

We found a high burden of visual impairment among the children. For every 10 patients seen in the pediatric eye clinic, 4 will present with visual impairment. This is a high prevalence compared to a similar setting. In Nigeria, they reported a prevalence of $29.3 \%$. However unlike our study, this was a community based study. Only those in need of the hospital services come to hospital compared to the community where everyone is seen regardless of their need for the given service.

Children between 5 to 12 years were 1.7 times more likely to suffer from visual impairment and children above 12 years were 2.5 times more likely to suffer from visual impairment as compared to the children below 5 years. Children who had sustained ocular trauma were 5.3 times more likely to suffer from visual impairment. Other factors with a strong association to visual impairment included; refractive errors, cataract, ocular infections and tumors. All these can be preventable or managed to pre- 
vent visual impairment in a child.

\section{Etiology for childhood visual impairment.}

Trauma was among the top etiologies for childhood visual impairment during the study period. This correlates with the findings in the study on causes of childhood visual impairment in East Africa ${ }^{11}$. The study showed a high proportion of visually impaired children with corneal pathology, with most cases being due to trauma. Ocular trauma is the cause of blindness in approximately half a million people worldwide. Trauma is often the most important cause of unilateral loss of vision, particularly in developing countries. ${ }^{12}$

Refractive errors were found to be important with regards to visual impairment with 8 of the 22 children that presented with refractive errors being visually impaired with an overall occurrence of $2.52 \%$.

\section{Childhood visual impairment by anatomical site}

Among the children that were reviewed, extra ocular pathology, corneal pathology, pupillary defects and fundus pathology were found to be significant for visual impairment. This correlates with the WHO report on childhood visual impairment in the context of the VISION 2020 where corneal and retinal pathologies were found to be significant association with childhood visual impairment. Causes of severe childhood visual impairment and blindness were analyzed across the global social economic spectrum and retinal pathology (29\%), cornea pathology $(15 \%)$, whole globe $(16 \%)$, lens $(12 \%)$, optic nerve $12 \%$ and were found to be significant ${ }^{13}$.

\section{Conclusion}

Our study has shown a high burden of visual impairment among children in Uganda. These findings indicate that it is vital to screen all the children presenting to hospital for visual impairment. Majority of the causes of the visual impairment are preventable. We however recommend a wider population based study on the prevalence and causes of childhood visual impairment to give a more detailed insight in order for policies to be amended to emphasize childhood visual impairment.

\section{Limitations}

Our study was hospital based in a National Referral Hospital eye clinic which is a specialized clinic. This reduces the generalizability of our findings and does not give a general picture of the prevalence of childhood visual im- pairment of the general population.

\section{Abbreviations}

ANC, Antenatal care; CVI, Childhood Visual Impairment; MDGs, Millennium Development Goals; PBYs, Person Blind Years; ROP, Retinopathy of Prematurity; SVI, Severe Visual Impairment; TEM, Traditional eye medicine; WHO, World Health Organization.

\section{Competing interests}

The authors of this work declare that they have no competing interests.

\section{Authors' contributions}

PK, conceived the ideas with input from AAM and GW, $\mathrm{KS}, \mathrm{KJB}$ analyzed the data, made the initial draft of the manuscript and edited the manuscript with immense edits from AAM, PK and GW. All the authors have read and approved the final manuscript.

\section{Acknowledgements}

We thank our patients for offering to participate in the study. We are grateful to the Mulago hospital eye clinic staff and the department of Ophthalmology as well as the Clinical Epidemiology Unit at Makerere University College of Health Sciences for all the support.

\section{References}

1. Resnikoff S, Pascolini D, Etya'ale D, Kocur I, Pararajasegaram R, Pokharel GP, et al. Global data on visual impairment in the year 2002. Bulletin of the World Health Organization. 2004;8211:844-51.

2. Steinkuller PG, Du L, Gilbert C, Foster A, Collins ML, Coats DK. Childhood blindness. Journal of AAPOS : the official publication of the American Association for Pediatric Ophthalmology and Strabismus. 1999;31:26-32.

3. D'Arcy S, Scholz G, Gooding B. In 2007, the theme for World Sight Day was "Vision for Children". In developed countries like Australia, eye disease and vision loss predominantly affect older people. A day focusing on "Vision.

4. Kocur I, Resnikoff S. Visual impairment and blindness in Europe and their prevention. British Journal of Ophthalmology. 2002;867:716-22.

5. Johnson GJ, Minassian DC, Weale RA, West SK. The Epidemiology of Eye Disease: Arnold; 2003.

6. Rahi JS, Gilbert CE, Foster A, Minassian D. Measuring the burden of childhood blindness. British Journal of Ophthalmology. 1999;834:387-8. 
7. Pascolini D, Mariotti SP. Global estimates of visual impairment: 2010. British Journal of Ophthalmology. 2011:bjophthalmol-2011-300539.

8. Israel GD. Determining sample size: University of Florida Cooperative Extension Service, Institute of Food and Agriculture Sciences, EDIS; 1992.

9. Adegbehingbe B, Taiwo O. Prevalence and pattern of childhood blindness in a resource limited teaching hospital in Nigeria. JOECS A. 2013;133.

10. Verweyen P. Measuring Vision in Children. Communi- tiy Eye Health Journal. 2004;1750:27-9.

11. Gilbert CE, Waddel K, Wood M, Foster A. Causes of childhood blindness in east Africa: results in $491 \mathrm{pu}-$ pils attending 17 schools for the blind in Malawi, Kenya and Uganda. Ophthalmic Epidemiology. 1995;22:77-84.

12. Thylefors B. Epidemiological patterns of ocular trauma. Australian and New Zealand Journal of Ophthalmology. 1992;202:95-8.

13. Gilbert C, Foster A. Childhood blindness in the context of VISION 2020: the right to sight. Bulletin of the 